EVALUASI, 3(2), September 2019, ISSN 2580-3387 (print) |

ISSN 2615-2886 (online)

Homepage : http://e-journal.staima-alhikam.ac.id/index.php/evaluasi

DOI $\quad$ : http://doi.org/10.32478/evaluasi.v3i2.270

Article type : Book review

\title{
EVALUASI PENDIDIKAN PERSPEKTIF ISLAM
}

(ANALISIS TAFSIR QS. QAFF AYAT 17-18)

Dwitri Stepanili, Hasbiyalah, Bambang Samsul A

1) UIN Sunan Gunung Djati Bandung, Jalan A.H. Nasution No. 105, Cipadung, Cibiru, Cipadung, Cibiru, Kota Bandung, Jawa Barat 40614

\begin{abstract}
This journal describes the Evaluation of Islamic Perspective Education. Assessment is intended to determine educational decisions, which consist of planning, management, process and follow-up of education, both involving individuals, groups and institutions. In this context, the assessment in Islamic perspective education is aimed at making decisions related to education truly in accordance with Islamic values so that the educational goals proclaimed can be achieved to the fullest. This evaluation system is based on the evaluation system outlined by Allah SWT, in the Koran and explained in the Sunna, which was carried out by the Prophet Muhammad in the process of fostering Islamic treatises. This research is a type of library research (library research), because the data source that will be explored is more focused on the study of literature: the written texts. Therefore this researcher will emphasize a qualitative approach.
\end{abstract}

Keyword : evaluation, education, Islam

\begin{abstract}
Abstrak
Jurnal ini menjelaskan tentang Evaluasi Pendidikan Perspektif Islam. Penilaian dimaksudkan untuk menetapkan keputusan-keputusan pendidikan, yang terdiri dari perencanaan, pengelolaan, proses dan tindak lanjut pendidikan, baik yang menyangkut perorangan, kelompok maupun kelembagaan. Dalam konteks ini, penilaian dalam pendidikan perspektif Islam bertujuan agar keputusan-keputusan yang berkaitan dengan pendidikan
\end{abstract}

Email address: dstepanili@gmail.com

EVALUASI: Jurnal Manajemen Pendidikan is licensed under

The CC BY License (https://creativecommons.org/licenses/by-sa/4.0/) 
EVALUASI, 3(2), September 2019, ISSN 2580-3387 (print)|

ISSN 2615-2886 (online)

http://doi.org/10.32478/evaluasi.v3i2.270

benar-benar sesuai dengan niai-nilai Islami sehingga tujuan pendidikan yang dicanangkan dapat tercapai secara maksimal. Sistem evaluasi ini berdasarkan pada sistem evaluasi yang digariskan oleh Allah SWT, dalam AIQuran dan dijelaskan dalam Sunah, yang dilakukan Rasulullah SAW dalam proses pembinaan risalah Islamiyah. Penelitian ini merupakan jenis penelitian kepustakaan (library research), karena sumber data yang akan digali lebih tertuju kepada studi kepustakaan: yakni naskah-naskah yang tertulis. Oleh karena itu peneliti ini akan menekankan pada pendekatan kualitatif.

Kata kunci: evaluasi, pendidikan, islam.

\section{A. PENDAhULUAN}

Pendidikan di Indonesia masih mengalami beragam problematika, yakni dilihat dari kurikulum, manajemen, ataupun subjek pendidikan itu sendiri. Sumber Daya Manusianya pun masih belum mencerminkan cita-cita pendidikan. Sebagai contoh masih terdapat beberapa kasus seperti siswa melakukan kecurangan pada saat ujian, banyak terjadi tawuran antar sesama siswa, bersikap malas, pergaulan bebas samapai terlibat narkoba. ${ }^{1} \mathrm{Di}$ sisi lain, masih ditemukan pula guru yang melakukan kecurangan-kecurangan dalam sertifikasi dan dalam penyelenggaraan ujian-ujian tertentu. Allah maha mengetahui malaikat-malaikat mulia yang bersama dengan kita dan mengetahui apa yang kita kerjakan. Setiap manusia ada malaikat yang mendampinginya dan dia memiliki bisikan-bisikan kepada manusia dengan bisikan kebaikan dan disisi lain ada syaitan yang senantiasa membisikkan keburukan-keburukan, oleh karenanya hendaknya kita malu kepada malaikat yang mulia yang melihat kita melakukan maksiat kepada Allah Subhanahu wata'ala.

\footnotetext{
${ }^{1}$ Purwanto,Ngalin. Evaluasi Pengajaran.Bandung: Remaja Karya, 1955.
} 


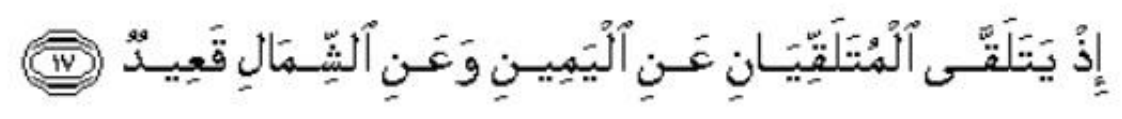

Artinya : "(yaitu) ketika dua orang malaikat mencatat amal perbuatannya, seorang duduk di sebelah kanan dan yang lain duduk di sebelah kiri"

Dalam ayat ini menjelaskana tentang berhati-hatilah mengerjakan sebuah perbuatan atau mengucapkan sebuah perkataan yang akan dituliskan untuknya dari hal-hal yang tidak diridhoi oleh Allah Subhanahu wata'ala, ada 2 malaikat yang menerima dan mencatat semua amalan hamba yang ia kerjakan, malaikat yang berada dikanan menuliskan kebaikan-kebaikan dan malaikat yang berada disebelah kiri menuliskan keburukan-keburukan yang dikerjakan dan ke dua malaikat ini senantiasa bersiap dan tidak pernah lalai mencatat semua apa yang pernah kita kerjakan dari kebaikan dan keburukan didunia ini.

Atas dasar inilah, maka pendidikan kita perlu direkonstruksi ulang agar dapat menghasilkan lulusan yang lebih berkualitas dan jujur serta penuh dengan problema dan tantangan serta dapat menghasilkan lulusan yang memiliki karakter mulia, yakni: memiliki kepandaian sekaligus kecerdasan, memiliki kreativitas tinggi sekaligus sopan dan santun dalam berkomunikasi, serta memiliki kejujuran dan kedisiplinan sekaligus memiliki tanggung jawab yang tinggi. Dengan kata lain, pendidikan harus mampu mengemban misi pembentukan karakter (character building) sehingga para peserta didik dan para lulusannya dapat berpartisipasi dalam mengisi pembangunan dengan baik dan berhasil tanpa meninggalkan nilai-nilai karakter mulia.

Untuk membangun manusia yang memiliki nilai-nilai karakter mulia seperti dirumuskan dalam tujuan pendidikan nasional, maka dibutuhkan sistem pendidikan yang memiliki materi yang lengkap (kaffah), serta ditopang oleh pengelolaan dan pelaksanaan yang benar dan baik. Pendidikan Islam memiliki tujuan yang seiring dengan tujuan pendidikan nasional. Secara umum pendidikan Islam mengemban misi utama memanusiakan manusia, 
EVALUASI, 3(2), September 2019, ISSN 2580-3387 (print)|

ISSN 2615-2886 (online)

http://doi.org/10.32478/evaluasi.v3i2.270

yakni menjadikan manusia mampu mengaktualisasikan seluruh potensi secara maksimal sesuai dengan aturan-aturan Allah SWT. ${ }^{2}$

Untuk mengetahui kualitas, kapasitas peserta didik perlu adanya evaluasi. Dalam evaluasi terdiri atas teknik, dan sasaran untuk menuju keberhasilan dalam proses belajar mengajar dan pendidikan secara keseluruhan. Evaluasi yang efektif harus didasarkan atas tujuan yang telah ditetapkan berdasarkan perencanaan dan kemudian benar-benar diusahakan oleh guru untuk peserta didik sehingga trcapai sasaran tujuan evaluasi tersebut. $^{3}$

\section{B. PEMBAHASAN}

\section{Pengertian Evaluasi Pendidikan}

Evaluasi merupakan suatu kegiatan yang terencana untuk mengetahui keadaan sesuatu obyek dengan menggunakan instrumen dan hasilnya dibandingkan dengan tolak ukur memperoleh kesimpulan. Secara sederhana dapat dimaknai bahwa evaluasi pendidikan adalah penilaian untuk mengetahui proses pendidikan dan komponen-komponennya dengan instrumen yang terukur. ${ }^{4}$ Dalam Undang-undang Nomor 20 Tahun 2003 tentang Sistem Pendidikan Nasional Bab I Pasal 1 ayat 21 dijelaskan bahwa evaluasi pendidikan adalah kegiatan pengendalian, penjaminan, dan penetapan mutu pendidikan terhadap berbagai komponen pendidikan pada setiap jalur, jenjang, dan jenis pendidikan sebagai bentuk per tanggungjawaban penyelenggaraan pendidikan.

Keberhasilan dari aktivitas pendidikan dapat dilihat dari pencapaian tujuannya. Upaya untuk mengetahui hal itu melalui penilaian atau evaluasi terhadap tingkat kemampuan peserta didik, serta pencapain dari tujuan yang telah ditetapkan. Dengan adanya evaluasi dapat diketahui apakah tujuan pendidikan sudah tercapai atau belum. Berdasarkan data dan informasi yang

\footnotetext{
2 Jamarah, Syaiful Bahri. Guru dan Anak didik dalam interaksi edukatif- Suatu Pendekatan Teoretis Psikologis. Jakarta: PT Rieneka Cipta, 2005.

${ }^{3}$ Arikunto, Suharsimi Arikunto. Dasar-dasar Evaluasi Pendidikan. Jakarta: PT Bumi Aksara, 2003.
} 
EVALUASI, 3(2), September 2019, ISSN 2580-3387 (print)|

ISSN 2615-2886 (online)

http://doi.org/10.32478/evaluasi.v3i2.270

diperoleh pula selanjutnya dilakukan berbagai kebijakan sebagai langkah perbaikan (Jalaluddin, 2016: 212).

Adapun jenis evaluasi dapat dibedakan sebagai berikut:

1) Jenis evaluasi berdasarkan tujuan dibedakan atas lima jenis evaluasi, yaitu:

a. Evaluasi diagnostik, adalah evaluasi yang di tujukan untuk menelaah kelemahan-kelemahan siswa beserta faktor-faktor penyebabnya.

b. Evaluasi selektif adalah adalah evaluasi yang digunakan untuk memilih siwa yang paling tepat sesuai dengan kriteria program kegiatan tertentu.

c. Evaluasi penempatan adalah adalah evaluasi yang digunakan untuk menempatkan siswa dalam program pendidikan tertentu yang sesuai dengan karakteristik siswa.

d. Evaluasi formatif adalah adalah evaluasi yang dilaksanakan untuk memperbaiki dan meningkatkan proses belajar dan mengajar formative evaluation looks at the process of Learning and teaching while the instruction disain is being develop and materials produced

e. Evaluasi sumatif adalah adalah evaluasi yang dilakukan untuk menentukan hasil dan kemajuan belajar siswa. Penilaian ini dilaksanakan terhadap program/ desain yang telah diimplementasikan.

2) Jenis evaluasi berdasarkan sasaran

a. Evaluasi konteks yang ditujukan untuk mengukur konteks program baik mengenai rasional tujuan, latar belakang program, maupun kebutuhan-kebutuhan yang muncul dalam perencanaan

b. Evaluasi input, evaluasi yang diarahkan untuk mengetahui input baik sumber daya maupun strategi yang digunakan untuk mencapai tujuan.

c. Evaluasi proses, evaluasi yang ditujukan untuk melihat proses pelaksanaan, baik mengenai kalancaran proses, kesesuaian 
EVALUASI, 3(2), September 2019, ISSN 2580-3387 (print)|

ISSN 2615-2886 (online)

http://doi.org/10.32478/evaluasi.v3i2.270

dengan rencana, faktor pendukung dan faktor hambatan yang muncul dalam proses pelaksanaan, dan sejenisnya.

d. Evaluasi hasil atau produk, evaluasi yang diarahkan untuk melihat hasil program yang dicapai sebagai dasar untuk menentukan keputusan akhir, diperbaiki, dimodifikasi, ditingkatkan atau dihentikan

e. Evaluasi outcome atau lulusan, evaluasi yang diarahkan untuk melihat hasil belajar siswa lebih lanjut, yakni evaluasi lulusan setelah terjun ke masyarakat.

3) Jenis evalusi berdasarkan lingkup kegiatan pembelajaran:

a. Evaluasi program pembelajaran, yang mencakup terhadap tujuan pembelajaran, isi program pembelajaran, strategi belajar mengajar, aspek-aspek program pembelajaran yang lain.

b. Evaluasi proses pembelajaran, yang mencakup kesesuaian antara peoses pembelajaran dengan garis-garis besar program pembelajaran yang di tetapkan, kemampuan guru dalam melaksanakan proses pembelajaran, kemampuan siswa dalam mengikuti proses pembelajaran.

c. Evaluasi hasil pembelajaran, mencakup tingkat penguasaan

b) siswa terhadap tujuan pembelajaran yang ditetapkan, baik umum maupun khusus, ditinjau dalam aspek kognitif, afektif, psikomotorik.

4) Jenis evaluasi berdasarkan objek dan subjek evaluasi Berdasarkan Objek antara lain:

a. Evaluasi input, evaluasi terhadap siswa mencakup kemampuan kepribadian, sikap, keyakinan.

b. Evaluasi transformasi, evaluasi terhadap unsur-unsur transformasi proses pembelajaran antara lain materi, media, metode dan lainlain.

c. Evaluasi output, evaluasi terhadap lulusan yang mengacu pada ketercapaian hasil pembelajaran.

Berdasarkan subjek : 
EVALUASI, 3(2), September 2019, ISSN 2580-3387 (print)|

ISSN 2615-2886 (online)

http://doi.org/10.32478/evaluasi.v3i2.270

a. Evaluasi internal, evaluasi yang dilakukan oleh orang dalam sekolah sebagai evaluator, misalnya guru.

b. Evaluasi eksternal, evaluasi yang dilakukan oleh orang luar sekolah sebagai evaluator, misalnya orangtua, masyarakat. ${ }^{4}$

\section{Tujuan dan Fungsi Evaluasi Pendidikan Perspektif Islam}

Secara filososis, pendidikan Islam bertujuan untuk membentuk allnsan al-Kamil (manusia paripurna). Olehkarena itu evaluasi pendidikan perspektif Islam, hendaknya diarahkan pada dua dimensi, yaitu: dimensi dialektikal horizontal dan dimensi ketundukan vertical. ${ }^{5}$ Tujuan evaluasi pendidikan adalah mengetahui kadar pemahaman anak didik terhadap materi pelajaran, melatih aktivitas peserta didik dalam mengingat kembali materi yang telah diberikan, melatih keberanian peserta didik dalam mengajak temannya kepada kegiatan akademik secara baik.

Tujuan evaluasi tidak hanya difokuskan pada anak didik saja, tetapi bertujuan mengevaluasi pendidik, yakni sejauh mana pendidik bersungguhsungguh dalam menjalankan tugasnya untuk mencapai tujuan pendidikan Islam. ${ }^{6}$ Dalam pendidikan Islam, tujuan evaluasi ditekankan pada penguasaan sikap, keterampilan dan pengetahuan-pemahaman yang berorientasi pada pencapaian al-insan al-kamil. ${ }^{7} \mathrm{Hal}$ ini bertujuan untuk mengetahui kemampuan peserta didik meliputi empat hal, yaitu:

1) Sikap dan pengalaman terhadap hubungan pribadinya dengan Tuhannya

2) Sikap dan pengalaman terhadap arti hubungan dirinya dengan masyarakat

\footnotetext{
${ }^{4}$ Purwanto,Ngalin. Evaluasi Pengajaran. Bandung: Remaja Karya, 1955.

5 Syaibany, Omaar Mohammad al-Toumu M. Falsafah Pendidikan Islam, Alih bahasa Dr. Hasan Langgulung, Jakarta: Cet. I, Bulan Bintang, 1979.

6 Ramayulis, Teknik Evaluasi Pendidikan agama Islam di Madrasah, Makalah, Fak. Tarbiyah IAIN Batusangkar,1996.
}

\footnotetext{
7 Samani, M. \& Hariyanto, Konsep dan Model Pendidikan Karakter.Bandung : PT. Remaja Rosdakarya. 2011. 
EVALUASI, 3(2), September 2019, ISSN 2580-3387 (print)|

ISSN 2615-2886 (online)

http://doi.org/10.32478/evaluasi.v3i2.270

3) Sikap dan pengalaman terhadap arti hubungan kehidupannya dengan alam sekitar; dan

4) Sikap dan pandangan terhadap dirinya sendiri selaku hamba Allah SWT, anggota masyarakat serta khalifah-Nya.

Menurut Suharna (2016: 28) evaluasi dilaksanakan secara obyektif, dalam arti bahwa evaluasi itu dilaksanakan dengan sebaik-baiknya, berdasarkan fakta dan data yang ada tanpa dipengaruhi oleh unsur-unsur subyektifitas dari evaluator (penilai). Dalam Al-Qur'an dijelaskan:

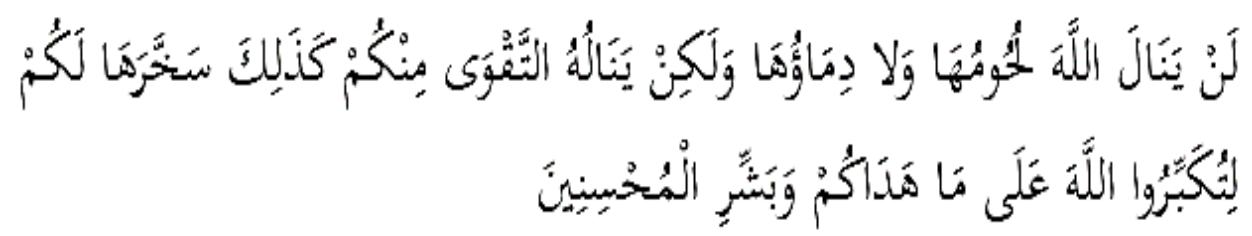

Artinya: Daging-daging unta dan darahnya itu sekali-kali tidak dapat mencapai (keridaan) Allah, tetapi ketakwaan dari kamulah yang dapat mencapainya. Demikianlah Allah telah menundukkannya untuk kamu supaya kamu mengagungkan Allah terhadap hidayah-Nya kepada kamu. Dan berilah kabar gembira kepada orang-orang yang berbuat baik. (Q.S. AI-Hajj: 37).

Allah SWT memerintahkan agar berlaku adil dalam mengevaluasi sesuatu, jangan karena kebencian menjadikan ketidakobjektifan evaluasi yang dilakukan (Q.S. Al-Maidah : 8). Dengan demikian, evaluasi harus menggambarkan kemampuan obyektif siswa yang sebenarnya, bukan berdasarkan suka dan tidak suka guru kepada para siswanya. Obyektivitas juga mengarah kepada perlakuan yang sama dan adil kepada semua murid yang dievaluasi dengan memberikan penilain yang fair atau adil.

Secara umum tujuan dan fungsi evaluasi pendidikan Islam sebagai berikut:

1) Untuk menguji. Hal ini digambarkan dalam Al-Quran tentang menguji daya kemampuan manusia beriman terhadap berbagai macam problema kehidupan yang dihadapi

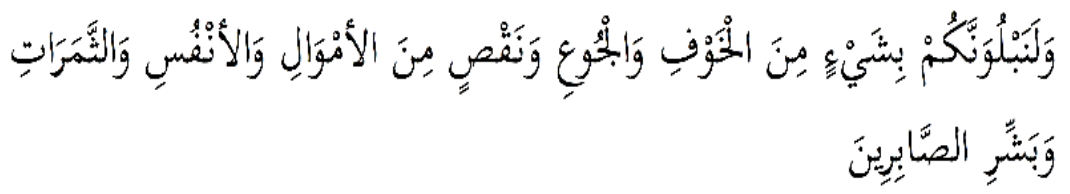


EVALUASI, 3(2), September 2019, ISSN 2580-3387 (print)|

ISSN 2615-2886 (online)

http://doi.org/10.32478/evaluasi.v3i2.270

Artinya: Dan sungguh Kami berikan cobaan kepadamu, dengan sedikit ketakutan, kelaparan, kekurangan harta, jiwa dan buah buahan. Dan berikanlah berita gembira kepada orang-orang yang sabar. (QS. AlBaqarah:155)

2) Untuk mengetahui. Hal ini digambarkan dalam Al-Quran tentang sejauh mana atau sampai dimana hasil pendidikan wahyu yang telah diaplikasikan Rasulullah SAW kepada umatnya

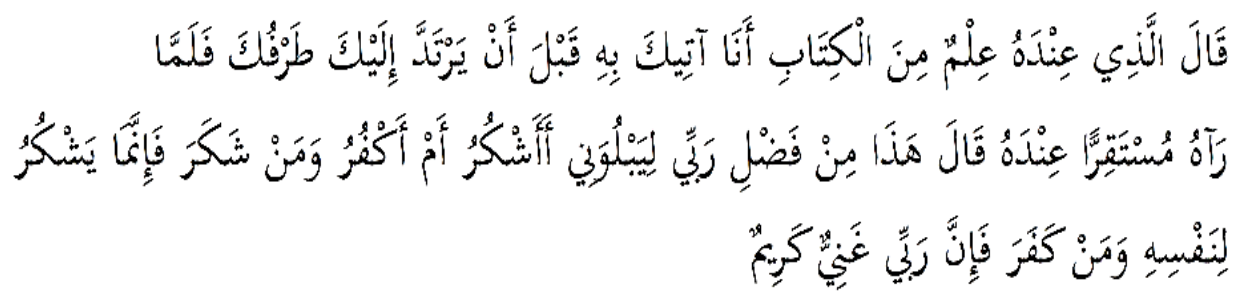

Artinya: Berkatalah seseorang yang mempunyai ilmu dari Al-Kitab: "Aku akan membawa singgasana itu kepadamu sebelum matamu berkedip". Maka tatkala Sulaiman melihat singgasana itu terletak di hadapannya, iapun berkata: "Ini termasuk kurnia Tuhanku untuk mencoba aku apakah aku bersyukur atau mengingkari (akan nikmat-nikmat-Nya). Dan barang siapa yang bersyukur maka sesungguhnya dia bersyukur untuk (kebaikan) dirinya sendiri dan barang siapa yang ingkar, maka sesungguhnya Tuhanku Maha Kaya lagi Maha Mulia". (QS. Al-Naml: 40)

3) Untuk menentukan klasifikasi atau tingkat. Hal ini digambarkan dalam ayat Al-Quran tentang klasifikasi atau tingkat hidup keislaman atau keimanan seseorang, seperti pengevaluasian Allah SWT. terhadap Nabi Ibrahim as. yang menyembelih Islamil as. putra dicintainya

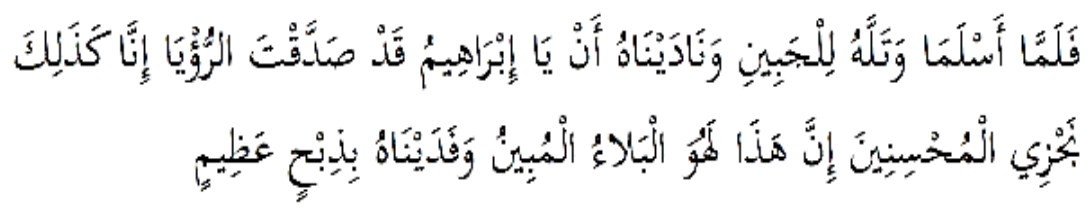

Artinya: Tatkala keduanya telah berserah diri dan Ibrahim membaringkan anaknya atas pelipis (nya), (nyatanya kesabaran keduanya). Dan Kami panggillah dia: "Hai Ibrahim, sesungguhnya kamu telah membenarkan mimpi itu", sesungguhnya demikianlah Kami memberi balasan kepada orang-orang yang berbuat baik. Sesungguhnya ini benar-benar suatu ujian yang nyata. Dan kami tebus anak itu dengan seekor sembelihan yang besar. (QS. Al-Shaffat: 103-107) 
EVALUASI, 3(2), September 2019, ISSN 2580-3387 (print)|

ISSN 2615-2886 (online)

http://doi.org/10.32478/evaluasi.v3i2.270

4) Untuk mengukur daya kognisi, hafalan manusia dan pelajaran yang telah diberikan kepadanya, seperti pengevaluasian terhadap nabi Adam as. tentang asma' yang diajarkan Allah SWT. kepadanya di hadapan para malaikat.
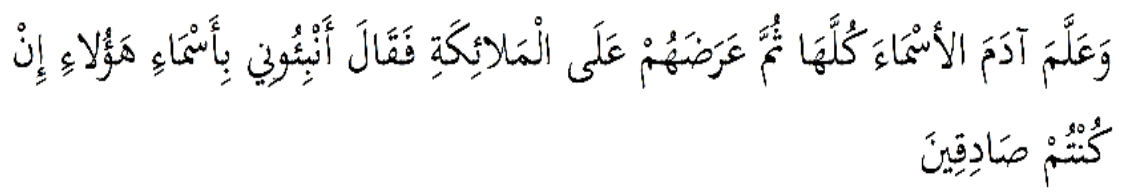

Artinya: Dan Dia mengajarkan kepada Adam nama-nama (benda-benda) seluruhnya, kemuadian mengemukakannya kepada para Malaikat lalu berfirman:"Sebutkanlah kepada-Ku nama benda-benda itu jika kamu memang orang-orang yang benar!" (QS. Al-Baqarah: 31)

5) Memberikan semacam tabsyir (berita gembira)/reward bagi yang beraktivitas baik, dan memberikan semacam 'iqlab (siksa) /punishment bagi mereka yang beraktivitas buruk

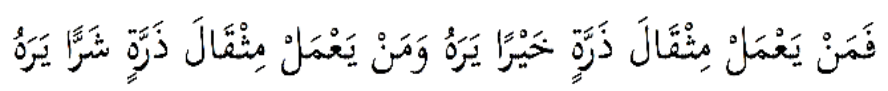

Artinya: Barang siapa yang mengerjakan kebaikan seberat zarah pun, niscaya dia akan melihat (balasan) nya. Dan barang siapa yang mengerjakan kejahatan seberat zarah pun, niscaya dia akan melihat (balasan) nya pula. (QS. Al-Zalzalah: 7-8).

Menurut Nazar Al Masri (2014: 236), fungsi evaluasi pendidikan islam adalah:

a. Islah, yaitu perbaikan terhadap semua komponen pendidikan, termasuk perbaikan perilaku, wawasan, dan kebiasaan-kebiasaan peserta didik

b. Tazkiyah, yaitu penyucian terhadap semua komponen pendidikan

c. Tajdid, yaitu memodernisasikan semua kegiatan pendidikan

d. Al-dakhkil, yaitu masukan sebagai bagi orang tua peserta didik.

Evaluasi pendidikan dilaksanakan mempunyai tujuan yang dapat menjadi tolak ukur keberhasilan proses pendidikan yang dilakukan. Tujuan evaluasi adalah untuk mengembangkan suatu kebijakan yang bertanggung jawab mengenai pendidikan (Tayibnapis, 2000: 3). 


\section{Tafsir Q.S. Qaf 17-18}

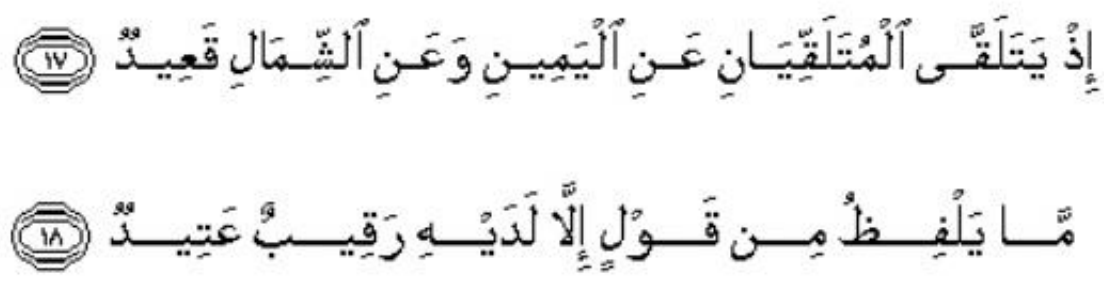

Artinya : "(yaitu) ketika dua orang malaikat mencatat amal perbuatannya, seorang duduk di sebelah kanan dan yang lain duduk di sebelah kiri. Tiada suatu ucapanpun yang diucapkannya melainkan ada di dekatnya malaikat pengawas yang selalu hadir."

Tafsir Jalalin

Ingatlah ketika lafal idz di sini dinashabkan oleh lafal udzkur yang keberadaannya diperkirakan (mencatat) yakni menulis (dua malaikat pencatat amal) artinya, yang diserahi tugas oleh allah untuk mencatat amal perbuatan yang dilakukan oleh manusia (yang satu berada di sebelah kanan dan yang lain berada di sebelah kiri) manusia (dalam keadaan duduk) yakni keduanya duduk, lafal qa'iid ini adalah mubtada dan khabarnya adalah lafal sebelumnya. ${ }^{8}$

Ibnu Katsir

Para malaikatlah yang turun membawa wahyu Al-Qur'an dengan seizin Allah SWT. Demikian pula para malaikatlah yang lebih dekat kepada manusia daripada urat lehernya berkat kekuasaan Allah SWT. yang diberikan kepada mereka untuk hal tersebut. Maka malaikat itu mempunyai jalan masuk ke dalam manusia sebagaimana setan pun mempunyai jalan masuk ke dalam manusia melalui aliran darahnya, seperti yang telah diberitakan oleh Nabi SAW. ${ }^{9}$ Karena itulah maka disebutkan oleh firman-Nya: (yaitu) ketika dua malaikat mencatat amal perbuatannya (Qaf: 17) Yakni dua malaikat yang

8 Syaibany, Omaar Mohammad al-Toumu M. Falsafah Pendidikan Islam, Alih bahasa Dr. Hasan Langgulung, Jakarta: Cet. I, Bulan Bintang, 1979.

9 Al-Aziz, Abdul dkk. Dalam Hasan Langgulung, Pendidikan dan peradaban Islam, al-Hasan. Jakarta: Indonesia, 1985. 
ditugaskan oleh Allah Swt. untuk mencatat amal perbuatan manusia. yang satu duduk di sebelah kanan dan yang lain duduk di sebelah kiri. (Qaf: 17) Artinya, keduanya selalu mengawasi. Tiada suatu ucapan pun yang diucapkannya, melainkan ada di dekatnya malaikat pengawas yang selalu hadir. (Qaf: 18) Yaitu tiada suatu kalimat pun yang dikatakannya, melainkan ada malaikat yang selalu mengawasinya dan mencatatnya; tiada suatu kalimat pun yang tertinggal, dan tiada suatu gerakan pun yang tidak tercatat olehnya. Semakna dengan apa yang disebutkan oleh firman-Nya : padahal sesungguhnya bagi kamu ada malaikat-malaikat yang mengawasi (pekerjaanmu), yang mulia (di sisi Allah) dan yang mencatat (pekerjaanpekerjaanmu itu), mereka mengetahui apa yang kamu kerjakan. Ingatlah ketika dua malaikat mencatat perbuatan manusia, yang satu duduk di sebelah kanan, yaitu malaikat yang mencatat kebaikan dan yang lain di sebelah kiri, yaitu malaikat yang mencatat kejahatan. $18^{10}$. Tidak ada suatu kata yang diucapkannya, yang mengandung keba-ikan maupun kejahatan, melainkan ada di sisinya malaikat pengawas yang selalu siap mencatat dengan sangat teliti.

\section{Kesimpulan}

Evaluasi pendidikan perspektif Islam merupakan penilaian untuk mengetahui proses pendidikan dan komponen-komponennya dengan instrumen yang terukur dan berlandaskan pada nilai-nilai yang terkandung dalam Al-Quran. Tujuan evaluasi pendidikan perspektif adalah mengetahui kadar pemahaman anak didik terhadap materi pelajaran, melatih keberanian dan mengajak anak didik untuk mengingat kembali materi yang telah diberikan. Program evaluasi bertujuan mengetahui siapa di antara peserta didik yang cerdas dan yang lemah, sehingga naik tingkat, kelas maupun tamat. Tujuan evaluasi bukan anak didik saja, tetapi bertujuan mengevaluasi pendidik, yaitu sejauh mana pendidik bersungguh-sungguh dalam menjalankan tugasnya untuk mencapai tujuan pendidikan Islam. Ada beberapa prinsip yang harus diperhatikan dalam evaluasi pendidikan Islam, yaitu: prinsip kontinuitas, prinsip menyeluruh, prinsip obyektivitas, dan prinsip mengacu pada tujuan. Dalam implementasi evaluasi dalam

10 Ramayulis, Teknik Evaluasi Pendidikan agama Islam di Madrasah, Makalah, Fak. Tarbiyah IAIN Batusangkar,1996. 
EVALUASI, 3(2), September 2019, ISSN 2580-3387 (print) |

ISSN 2615-2886 (online)

http://doi.org/10.32478/evaluasi.v3i2.270

pendidikan karakter memang tidak semudah membalik tangan, namun itu semua adalah tantangan bagi dunia pendidikan sekarang dan masa mendatang. Jika dalam pembelajaran guru belum mampu mengevaluasi siswa dalam evaluasi pendidikan karakter maka harus ada korelasi positif dengan lingkungan sekitar misal keluarga dan masyarakat.

\section{DAFTAR PUSTAKA}

Arikunto, Suharsimi Arikunto. Dasar-dasar Evaluasi Pendidikan. Jakarta: PT Bumi Aksara, 2003.

Al-Aziz, Abdul dkk. Dalam Hasan Langgulung, Pendidikan dan peradaban Islam, al-Hasan. Jakarta: Indonesia, 1985.

Azra, Azyumardi. Catatan tentang Evaluasi atas arah pendidikan serta fungsionalisasi Pemikiran Pendidikan di Indonesia. Makalah pada Diskusi

Jamarah, Syaiful Bahri. Guru dan Anak didik dalam interaksi edukatif- Suatu Pendekatan Teoretis Psikologis. Jakarta: PT Rieneka Cipta, 2005.

Purwanto,Ngalin. Evaluasi Pengajaran.Bandung: Remaja Karya, 1955.

Ramayulis, Teknik Evaluasi Pendidikan agama Islam di Madrasah, Makalah, Fak. Tarbiyah IAIN Batusangkar,1996.

Soeharto, Karti. Teknologi Pembelajaran, Pendekatan sistem, konsepsi dan model, SAP, evaluasi, sumber belajar dan Media. Surabaya : SIC advertising, 2003.

Wand Edwin and General W. Brown, Essential of educational Evaluation. New York: 1979, vol 27.

Syaibany, Omaar Mohammad al-Toumu M. Falsafah Pendidikan Islam, Alih bahasa Dr. Hasan Langgulung, Jakarta: Cet. I, Bulan Bintang, 1979.

Samani, M. \& Hariyanto, Konsep dan Model Pendidikan Karakter.Bandung : PT. Remaja Rosdakarya. 2011 